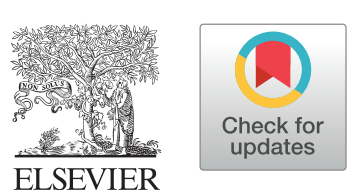

\title{
Review
}

\section{Moving Together While Staying Apart: Practical Recommendations for 24-Hour Home-Based Movement Behaviours for Those With Cardiovascular Disease}

\author{
Carley D. O’Neill, PhD, ${ }^{a}$ Sol Vidal-Almela, MSc, ${ }^{\text {a,b,c }}$ Tasuku Terada, PhD, ${ }^{a}$ \\ Kimberley L. Way, PhD, ${ }^{a, d}$ Kentaro Kamiya, PhD, ${ }^{e}$ Billy Sperlich, PhD, ${ }^{f}$ Peter Duking, PhD, \\ Jean-Phillipe Chaput, PhD, ${ }^{c, g, h}$ Stephanie A. Prince, PhD, ${ }^{g, i}$ Andrew L. Pipe, MD, ${ }^{a, j}$ and \\ Jennifer L. Reed, PhD ${ }^{\mathrm{a}, \mathrm{c}, \mathrm{g}}$ \\ ${ }^{a}$ Exercise Physiology and Cardiovascular Health Lab, Division of Cardiac Prevention and Rehabilitation, University of Ottawa Heart Institute, Ottawa, Ontario, Canada \\ ${ }^{b}$ Institut du savoir Montfort, Hôpital Montfort, Ottawa, Ontario, Canada \\ ${ }^{c}$ School of Human Kinetics, Faculty of Health Sciences, University of Ottawa, Ottawa Ontario, Canada \\ ${ }^{d}$ Institute for Physical Activity and Nutrition, Deakin University, Geelong, Victoria, Australia \\ ${ }^{e}$ School of Allied Health Sciences, Kitasato University, Kanagawa, Japan \\ ${ }^{f}$ Department of Sports Sciences, University of Wuerzburg, Wurzburg, Bavaria, Germany \\ ${ }^{g}$ School of Epidemiology and Public Health, Faculty of Medicine, University of Ottawa, Ottawa, Ontario, Canada \\ ${ }^{h}$ Healthy Active Living and Obesity Research Group, CHEO Research Institute, Ottawa Ontario, Canada \\ ${ }^{i}$ Centre for Surveillance and Applied Research, Public Health Agency of Canada, Ottawa Ontario, Canada \\ ${ }^{j}$ Department of Medicine, Faculty of Medicine, University of Ottawa, Ottawa, Ontario, Canada
}

\section{ABSTRACT}

The novel coronavirus disease 2019 is a global public health crisis that disproportionately affects those with preexisting conditions. Cardiovascular disease (CVD) is the leading cause of death worldwide and many key CVD risk factors are modifiable (e.g., physical inactivity, sedentary behaviour, obesity). To limit the spread of coronavirus 2019, most governments have implemented restrictions and recommended staying at home, reducing social contact to a select and exclusive few, and limiting large gatherings. Such public health constraints may have unintended, negative health consequences on 24-hour movement behaviours. The primary purpose of this review is to provide practical at-home recommendations for sedentary time, sleep, and physical

The novel coronavirus disease 2019 (COVID-19) is a highly contagious, viral respiratory illness that has afflicted $\geq 254$ million people globally and resulted in $\geq 5.1$ million deaths as of November 16, 2021. ${ }^{1}$ Adults with cardiovascular disease

Received for publication June 7, 2021. Accepted August 21, 2021.

Ethics Statement: No ethics approval was required.

Corresponding author: Dr Jennifer Reed, Exercise Physiology and Cardiovascular Health Lab, University of Ottawa Heart Institute, 40 Ruskin

St, Ottawa, Ontario K1Y 4W7, Canada.

E-mail: jreed@ottawaheart.ca

See page 1502 for disclosure information.

\section{RÉSUMÉ}

La nouvelle maladie à coronavirus 2019 représente une crise de santé publique mondiale qui touche de manière disproportionnée les personnes présentant des pathologies préexistantes. Les maladies cardiovasculaires (MCV) constituent la principale cause de décès dans le monde et de nombreux facteurs de risque majeurs de MCV sont modifiables (par exemple, le manque d'activité physique, un comportement sédentaire, l'obésité). Pour limiter la propagation du coronavirus 2019, la plupart des gouvernements ont mis en place des restrictions et recommandé de rester à la maison, de réduire les contacts sociaux à un nombre de personnes restreint et exclusif, et de limiter les grands rassemblements. Ces contraintes de santé publique

(CVD) have an increased risk of morbidity and premature mortality from COVID-19 (approximately 10\% of those with preexisting CVD who contract COVID-19 will die). ${ }^{2,3}$ To limit the spread of COVID-19, public health authorities have implemented mobility restrictions (eg, quarantine, selfisolation) and commercial closures, including many fitness facilities. The closure of in-person cardiac rehabilitation programs resulted in the transition to virtual program offerings ${ }^{4}$; not all programs or patients, however, have access to the necessary resources (eg, funds, technology, Internet connection) to transition effectively. There is therefore a need to 
activity in those living with CVD. Adults with CVD will benefit from practical recommendations to reduce sedentary time, increase purposeful exercise, and maintain optimal sleep patterns while being at home and adhering to public health restrictions. Our recommendations include the following: (i) self-monitoring sitting time; (ii) engaging in 23 days per week of purposeful exercise for those with low exercise capacity and $>3$ days per week for those with moderate-to-high exercise capacity; (iii) self-monitoring exercise intensity through the use of scales or wearable devices; (iv) maintaining a regular sleep schedule; and (v) moving daily. Clinicians should be aware that clear communication of the importance of limiting prolonged sedentary time, engaging in regular physical activity and exercise, and ensuring optimal sleep in association with the provision of clear, comprehensible, and practical advice is fundamental to ensuring that those living with CVD respond optimally to the challenges posed by the pandemic.

provide patients with the tools required to ensure healthy, 24hour movement behaviours (ie, limit sedentary time, optimal, and regular physical activity; any movement carried out by the muscles that requires energy). Most governments had recommended staying home, reducing social contact, and limiting large gatherings, but subsequent surges of infections caused a return to earlier restrictions. Such public health constraints may have unintended negative health consequences as 24-hour movement behaviours were altered globally, with increased sedentary time, ${ }^{5}$ reduced physical activity and purposeful exercise, ${ }^{5,6}$ and unhealthy (eg, too much or too little) sleeping patterns. ${ }^{7}$ These changes pose significant risk to the health of individuals and can contribute to declines in physical and mental health during the pandemic. ${ }^{8}$

COVID-19 public health restrictions have increased sedentary behaviour. ${ }^{5,9}$ Strong evidence supports a positive relationship between greater sedentary behaviour and type 2 diabetes, metabolic syndrome, ${ }^{10}$ heightened levels of anxiety ${ }^{11}$ and depression, ${ }^{12}$ and all-cause mortality. ${ }^{13}$ Amid the COVID-19 pandemic, sedentary time has increased substantially, and low-intensity physical activity and step counts have declined significantly. ${ }^{14}$ These findings are of particular significance for those living with CVD, as pre-pandemic sedentary time was already shown to be higher among these individuals. ${ }^{15}$ Recommendations for replacing sedentary time with physical activity while adhering to pandemic public health recommendations are warranted to help reduce the burden of CVD. ${ }^{16}$

Regular aerobic and resistance exercise (ie, planned, structured, intentional movement with the aim of maintaining or improving physical fitness and health) are associated with numerous physical (eg, lower blood pressure, higher cardiorespiratory fitness, enhanced sleep quality) and mental (eg, lower levels of anxiety and depression) health benefits among adults with CVD. ${ }^{17,18}$ Moderate-intensity aerobic exercise is associated peuvent involontairement entraîner des conséquences sanitaires négatives sur les habitudes de déplacement sur 24 heures. L'objectif principal de cette étude est de fournir des recommandations pratiques, réalisables à domicile, en rapport avec le temps de sédentarité, le sommeil et l'activité physique chez les personnes atteintes de MCV. Les adultes atteints de MCV tireront avantage de recommandations pratiques dans le but de réduire le temps de sédentarité, augmenter l'activité physique volontaire et maintenir des habitudes de sommeil optimales, tout en restant à la maison et en respectant les restrictions sanitaires. Nos recommandations sont les suivantes: (i) autosurveillance du temps passé assis; (ii) pratique d'une activité physique volontaire 2 à 3 jours par semaine pour les personnes ayant une faible capacité d'exercice et $>\mathbf{3}$ jours par semaine pour les personnes ayant une capacité d'exercice modérée à élevée; (iii) autosurveillance de l'intensité de l'activité par l'utilisation de barème ou de dispositifs portatifs; (iv) maintien d'horaires de sommeil réguliers; et (v) action de bouger quotidiennement. Les cliniciens doivent être conscients qu'une communication claire quant à l'importance de limiter le temps de sédentarité prolongée, de pratiquer régulièrement de l'exercice ou une activité physique, et d'assurer un sommeil optimal, associée à la préconisation de conseils clairs, compréhensibles et pratiques, est fondamentale pour garantir une réponse optimale de la part des personnes vivant avec des MCV quant aux défis posés par la pandémie.

with a reduction in respiratory infection rates, respiratory symptom burden, and mortality, ${ }^{19-21}$ underscoring the importance of maintaining an active lifestyle during the COVID-19 pandemic. Those infected with COVID-19 who are consistently inactive have been shown to be at an increased risk of hospitalization, admission to an intensive-care unit, and death as a result of the virus, in comparison to counterparts who participated in some physical activity and those who met the physical activity guidelines $(\geq 150$ minutes of moderate-vigorous physical activity per week). ${ }^{22}$ Aerobic and resistance-training exercise have additional benefits that aid in reducing the severity and burden of CVD, including improved cardiorespiratory and functional fitness and mental health, minimized agerelated decline in muscle mass, reduced risk of experiencing a second cardiac event, and reduced mortality. ${ }^{23,24}$ Access to exercise facilities has been limited during the pandemic, and those with preexisting health conditions are urged to take additional precautions by reducing time outside the home. These restrictions have led to a marked increase in web searches for community and "at-home" exercise guidance, ${ }^{25}$ underscoring the need for accessible, informative, and "pandemic-relevant" exercise recommendations.

Several authors have reinforced the importance of regular physical activity/exercise during the pandemic. ${ }^{5,26}$ They do not, however, provide practical recommendations as to how individuals living with CVD can engage in exercise and improve their 24-hour movement behaviours. Adults living with CVD will benefit from the application of 24-hour movement behaviour and exercise recommendations given that they are more: (i) susceptible to experiencing complications of $\mathrm{CVD}^{27}$; (ii) likely to be confined at home; and (iii) vulnerable to the detrimental effects of inactivity, sedentariness, and sleep disturbances on cardiovascular health. ${ }^{28}$

Healthy sleep (broadly defined as sleep of adequate duration, quality, and timing) plays a fundamental role in physical 
and mental health. ${ }^{29}$ Insufficient sleep ( $<7$ hours per night) is a global public health concern and is associated with CVD. ${ }^{30}$ A U-shaped relationship exists between sleep duration and CVD morbidity and mortality ${ }^{31}-$ too little or too much sleep has an impact on CVD. ${ }^{31}$ The incidence of reported sleep disturbances has markedly increased during the COVID-19 pandemic. $^{28}$ Stress, anxiety, changes in daily routines, and reduced daylight exposure are key disruptors of sleep and circadian rhythms, and these have been more prominent during the pandemic. ${ }^{28}$ Conversely, some people have reported improved sleep amid the pandemic, owing to reduced rigidity in work/school schedules. ${ }^{32}$

There is a need to adapt daily regimens during the COVID-19 pandemic to ensure that adults living with CVD can achieve optimal 24-hour movement and exercise profiles while following public health restrictions for COVID-19. The primary purpose of this paper is to provide healthcare professionals and patients with a comprehensive resource with practical recommendations for achieving, maintaining, and monitoring healthy 24-hour movement behaviours for adults living with stable CVD during a pandemic. Educational resources have also been provided for physicians, physiotherapists, kinesiologists, and exercise physiologists/scientists to share widely with their patients. Figure 1 illustrates the interconnectedness of the 24-hour movement behaviours amid the pandemic.

\section{4-Hour Movement Behaviour Recommendations}

Table 1 provides a summary of the 24-hour movement behaviour recommendations discussed within this review. At a minimum, any movement is better than no movement, prolonged bouts of sedentary behaviour should be reduced, and regular light-intensity movement should be encouraged.

\section{Sedentary Behaviour}

Greater mortality risks have been associated with $>9-10$ hours of device-assessed sedentary time, ${ }^{16}>7-8$ hours of selfreported sitting time, ${ }^{13}$ and $>3 \mathrm{~h} / \mathrm{d}$ of television viewing. ${ }^{33}$ The risks are comparable among those living with CVD. ${ }^{34,35}$ There is evidence that moderate-to-vigorous-intensity physical activity (MVPA) may reduce or negate the effects associated with prolonged television viewing and total sitting time (30-40 to 60$75 \mathrm{~min} / \mathrm{d}){ }^{36}$ This finding is troubling given that, globally, very few adults $(27.5 \%)$ currently meet such physical activity guidelines. ${ }^{37}$ Important to note is evidence showing that the total volume of sedentary time is not solely responsible for placing individuals at greater risk for poor health outcomes; the pattern in which this time is accrued also plays a role. ${ }^{38}$ Individuals who frequently break up their sedentary time (ie, accrue sedentary time in bouts $<30$ minutes) have a lower risk of mortality, compared to those who spend more time in longer sedentary bouts. ${ }^{39}$ Experimental studies have also found that breaking up sitting time with standing and movement can result in favourable metabolic changes and improve cardiovascular risk factors (eg, reduced weight, waist circumference, and blood pressure). ${ }^{40,41}$

The public health response to the COVID-19 pandemic (eg, social distancing, closing of many recreational and occupational venues) has resulted in an increase in sedentariness (eg, screen usage/watching). ${ }^{5}$ In Canada, survey data revealed that during the pandemic's first wave, most adults reported spending more time on the Internet (68\%), watching television (63\%), and playing video games (22\%). 9 Maintaining and decreasing screen time related to television and video game usage were associated with superior self-rated physical and mental health.' Global movement data collected using smartphone technology identified that daily step counts decreased sharply during the first 10 days of the pandemic declaration; these reductions were sustained over a 30 -day period. ${ }^{42}$ The declines varied regionally, with more dramatic reductions among countries with stricter social-distancing protocols. ${ }^{42}$ Steps are highly correlated with sedentary behaviour, as they reflect ambulatory and sporadic daily movement. ${ }^{43}$

During the COVID-19 pandemic, the World Health Organization (WHO) released a guidance document addressing physical activity and sedentary behaviour during self-quarantine for those without symptoms or diagnosis of acute respiratory illness. ${ }^{44}$ The tips provided for remaining active and reducing sedentary behaviour include the following: (i) take short active breaks during the day; (ii) follow an online exercise class; (iii) walk, even in small spaces; (iv) stand up, to reduce sedentary time, and consider creating a standing desk; and (v) relax using meditation and deep breathing. These recommendations are consistent with the recent release from the Canadian Society for Exercise Physiology, including a new 24-hour movement guideline for adults (18-64 years and $65+$ years). ${ }^{45}$ Our additional practical tips for reducing sedentary behaviour during the COVID-19 pandemic among those with CVD include the following: (i) self-monitor movement behaviours by using a wearable device or recording the time you spend sitting; being aware of how much you sit and when you sit for long periods (eg, working at a computer, watching television) is important, to understand where you can make changes; (ii) set up the home environment to encourage movement (eg, move your wastebasket away from your home office, leave the remote controls across the room); (iii) drink water regularly-this promotes frequent trips to the bathroom; (iv) set up external cues/idle alerts through the use of wearables, smart phone apps, or activity alarms to prompt you to stand every 20-30 minutes; (v) create habit reminders by standing or moving during routine habits (eg, choose to stand when having a drink, lap your home every time you use the washroom, or take phone calls standing); and (vi) engage in no more than 8 hours of sedentary time per day, including no more than 3 hours of recreational screen time. A review of techniques for reducing sedentary behaviour found that self-monitoring, problem solving, and restructuring the social or physical environment were the most promising techniques. ${ }^{46}$ Use of wearable devices and prompts and cues to get up and move can help promote reductions in time spent being sedentary in adults and among patients with CVD. ${ }^{47}$ Establishing sedentary-behaviour breaks during routine events will help form habits more easily. ${ }^{48}$ Evidence supports the interruption of sedentary bouts every 20-30 minutes, with 2 minutes or more of light-intensity physical activity. ${ }^{49}$

\section{Exercise}

\section{Aerobic exercise}

Pre-exercise considerations. Medical condition(s), risk factors, medications, and previous exercise history should be 

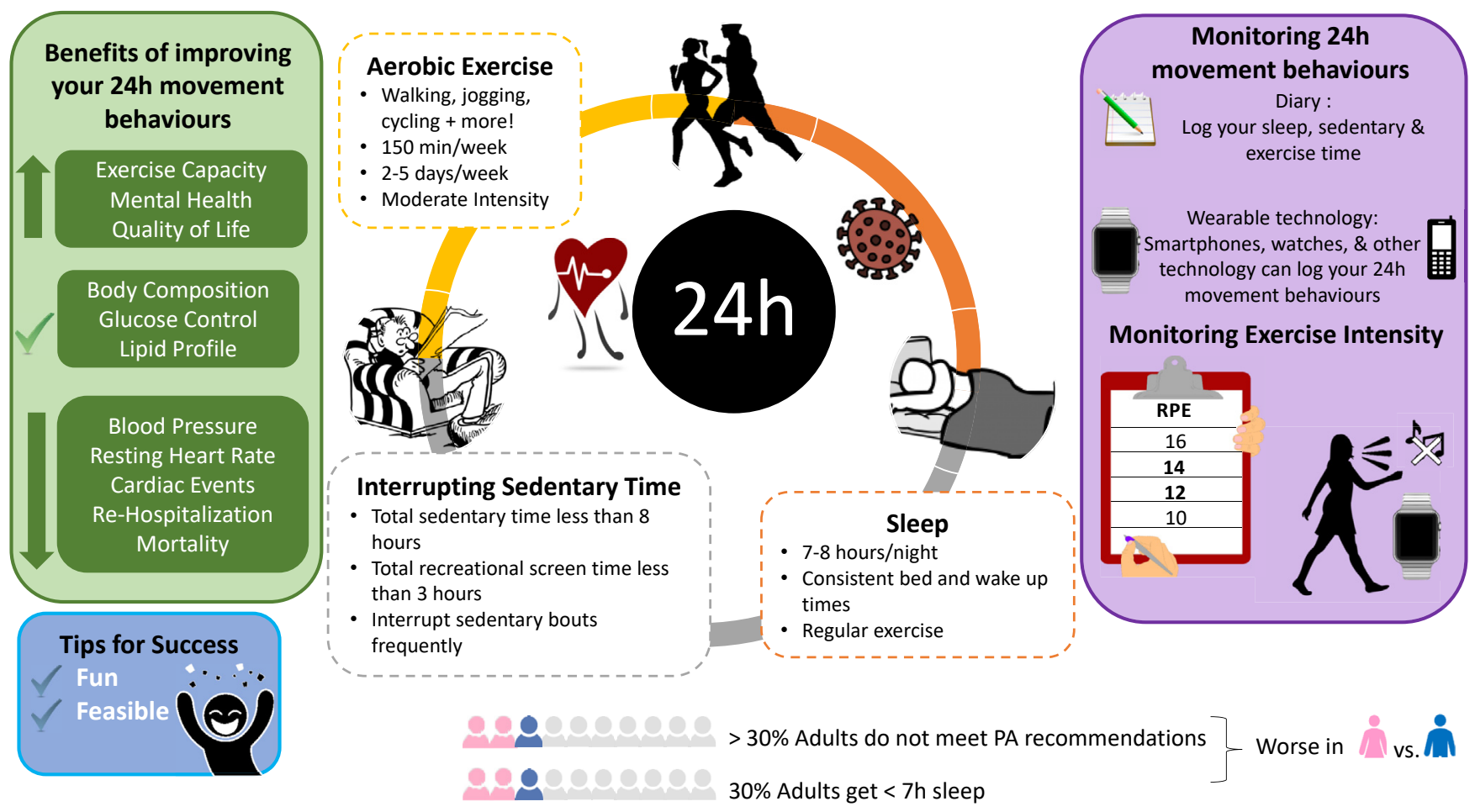

Figure 1. The interconnectedness of the 24-hour movement behaviours and exercise amid the pandemic is shown. PA, physical activity; RPE, Borg Rating of Perceived Exertion.

considered prior to providing exercise advice. National risk screening tools are readily available (eg, Canadian Society for Exercise Physiology, Get Active Questionnaire ${ }^{50}$; American College of Sports Medicine, Exercise Preparticipation Health Screening ${ }^{51}$ ) to ensure patients are cleared for exercise participation. It must be recognized, however, that the majority of patients can safely increase their normal levels of physical activity, and a little is much better than none! These tools can be completed virtually, or in-person via interaction between the healthcare provider and patient. It must be acknowledged that, during a pandemic, the introduction of exercise testing schema should reflect a practical, straightforward approach appropriate for the challenge of helping the sedentary become more active and supporting the development of increasing levels of regular physical activity for all.

Safety. Adults living with stable CVD are considered to be at moderate-to-high risk from exercise participation, according to the American College of Sports Medicine. ${ }^{52}$ Walking at a comfortable, self-limited pace, however, is safe for CVD patients. Prior to prescribing exercise, individuals should be made aware of symptoms that could occur during exercise and how to address them. Table 2 provides a summary of potential symptoms and how they can be managed during exercise at home, for those with stable CVD.

Principles of exercise prescription: frequency, intensity, time, type

Exercise prescription is composed of 4 principles: (i) frequency (number of sessions per week); (ii) intensity (exertion during exercise); (iii) time (duration of session); and (iv) type (mode of exercise) (FITT). For exercise to be safe and effective in improving physical and mental health, appropriate guidance incorporating all 4 principles is of paramount importance.

The current Canadian Association of Cardiovascular Prevention and Rehabilitation clinical guidelines recommend that patients with CVD engage in 20-60-minute exercise sessions at an intensity ranging from $40 \%$ to $85 \%$ heart rate (HR) reserve (HRR), 3-5 days per week. ${ }^{53}$ These recommendations

Table 1. 24-hour movement behaviour recommendations

\begin{tabular}{|c|c|c|c|}
\hline & Sedentary behaviour & Physical activity & Sleep \\
\hline Recommendations & $\begin{array}{l}\leq 8 \mathrm{~h} / \mathrm{d} \text {, including } \leq 3 \mathrm{~h} \text { recreational } \\
\text { screen time } \\
\text { - Breaking up long periods of sitting as } \\
\text { often as possible }\end{array}$ & $\begin{array}{l}150 \text { min moderate-to-vigorous physical } \\
\text { activity per week } \\
\text { - Muscle- strengthening activities using } \\
\text { major muscle groups at least twice a } \\
\text { week } \\
\text { - Several hours of light physical activ- } \\
\text { ities, including standing }\end{array}$ & $\begin{array}{l}\text { 7-9 h optimal sleep per night, with } \\
\text { consistent bed and wake-up times }\end{array}$ \\
\hline
\end{tabular}


Table 2. Symptoms to self-monitor during exercise ex2 $^{52}$

\begin{tabular}{ll}
\hline \hline Symptoms & \multicolumn{1}{c}{ Recommendation } \\
\hline Dizziness or lightheadedness & $\begin{array}{c}\text { Reduce intensity; hydrate with water or a } \\
\text { sports drink; sit or lie down }\end{array}$ \\
Excessive shortness of breath & $\begin{array}{l}\text { Reduce intensity; remain calm } \\
\text { Reduce intensity; cool down }\end{array}$ \\
Chest pain & $\begin{array}{l}\text { Reduce intensity; remain calm; call or have } \\
\text { a family member/friend call 911 }\end{array}$ \\
\hline
\end{tabular}

may seem arbitrary or complicated for patients aiming to exercise without supervision and lacking knowledge of how to monitor their physical activity behaviours. Consequently, specific, comprehensive, and practical recommendations for each exercise prescription principle are summarized below.

Frequency. Frequency refers to the number of days per week a person engages in exercise. Age, exercise capacity, and cardiovascular risk factors (eg, hypertension, diabetes, overweight/ obesity, lipid profile, and mental health status) are important considerations prior to recommending or prescribing exercise frequency; most guidelines emphasize simply moving toward increased physical activity most days of the week or more.

Exercise capacity considerations. Low exercise capacity at baseline: patients who have a low level of fitness $(<5$ metabolic equivalents [METS]) should begin exercising 2 days per week and increase to 3 days per week as fitness improves. Individuals who present with low exercise capacity may experience improvements and better adherence with $<3$ sessions per week; however, higher frequencies are likely to elicit greater improvements. 54,55

Moderate or high exercise capacity at baseline: Adults who have moderate-to-high levels of fitness ( $>5$ METS) should exercise at least 3 days per week and gradually increase to 5 days per week as fitness improves; the greatest exercise capacity improvements will occur with higher frequency of sessions. ${ }^{55}$

Considerations for patient's age. Higher exercise frequency reduces the risk of CVD among older adults (aged $>60$ years) ${ }^{56}$ and improves exercise capacity regardless of age; yet, some age-related considerations pertaining to exercise frequency have been suggested. Younger patients (aged $<50$ years) tend to have greater increases in fitness with a higher frequency of weekly aerobic exercise; older individuals (aged $>50$ years) may still achieve improvements in exercise capacity with a low frequency of sessions. ${ }^{55}$

Additional considerations. A single bout of exercise elicits acute benefits, including a reduction in post-exercise blood pressure $^{57}$ and blood glucose, ${ }^{58}$ and enhanced mood. ${ }^{59}$ These acute changes experienced regularly can substantially improve the CVD risk-factor profile. For example, MVPA performed 3-5 times per week lowers blood pressure by an average of 3.4/ $2.4 \mathrm{~mm} \mathrm{Hg} .{ }^{60}$ Less-frequent (2-3 days per week) sessions of longer duration (see time recommendations below) are successful for improving fitness levels; sustained, increased exercise frequency produces additional health benefits (eg, improved lipid profile, ${ }^{61}$ glucose control, ${ }^{62}$ quality of life, ${ }^{63}$ and reduced levels of anxiety and depression). ${ }^{64}$ Patients with time constraints, or those who prefer shorter exercise sessions, will benefit from a higher frequency of shortduration activity. ${ }^{55}$ Increasing the frequency of exercise sessions or incidental physical activity during the week can improve fitness levels.

Intensity. Intensity refers to the physical effort required for a given exercise bout. Current recommendations suggest engaging in physical activity within the moderate-to-vigorous range. ${ }^{\circ}$ Yet, sedentary patients can gain considerable health benefits from being active at lower levels of intensity on a regular basis. Thus, low-intensity physical activity is the preferred recommendation for patients who are unscreened for engaging in exercise participation in an unsupervised setting. For patients with CVD who have been encouraged by their clinician to participate in exercise, low-to-moderate-intensity physical activity is safe to recommend. Those patients interested in progressing to higher-intensity exercise should do so only after proper screening by a clinician. For those patients eager to progress from moderate- to high intensity exercise, consultation with their clinician and an exercise stress test to ensure safety, if recommended and available, should precede the progression. Important to recognize, however, is that cardiovascular health can be significantly and very safely enhanced by walking regularly at a comfortable pace.

Several methods can be used to monitor unsupervised exercise intensity. ${ }^{65}$ Valid and reliable scales such as the Borg Rating of Perceived Exertion (RPE), ${ }^{66}$ monitoring of heart rate (HR), the talk test, ${ }^{67}$ and wearable technologies can all be used with minimal equipment or expertise. Table 3 summarizes recommended methods for prescribing and monitoring low- and moderate-intensity exercise.

RPE scale. Prescribing and monitoring exercise intensity using the RPE scale is a simple and inexpensive option for patients. The Borg RPE scale is a 14-point Likert scale ranging from 6 (no exertion at all) to 20 (maximal exertion). ${ }^{68}$ RPE during exercise highly correlates with objective relative indices of exercise intensity ( $\%$ maximum oxygen uptake, \% maximum HR) in women and men, regardless of training status. ${ }^{69}$ RPE may be particularly useful for patients with

Table 3. Prescribing and monitoring exercise intensity among patients with stable cardiovascular disease in an unsupervised setting

\begin{tabular}{lcc}
\hline \hline & & Exercise intensity level \\
\cline { 2 - 3 } Tool & Low & Moderate \\
\hline Borg Rating of Perceived Exertion & $9-11$ & $12-13$ \\
Gellish equation, \% heart rate peak & $<57-63$ & $64-75$ \\
Talk test & Able to sing & Unable to sing but can maintain \\
& & conversation \\
\hline
\end{tabular}


Table 4. Heart rate prediction equations for monitoring exercise intensity

\begin{tabular}{|c|c|c|c|c|}
\hline Equation & $\begin{array}{l}\text { Population/method used to } \\
\text { develop equation }\end{array}$ & $\begin{array}{l}\text { Number of } \\
\text { men/women } \\
\text { in study }\end{array}$ & Strengths & Limitations \\
\hline \multicolumn{5}{|l|}{ Our recommended equation } \\
\hline Gellish et al. ${ }^{94}(207-0.7 \times$ age $)$ & $\begin{array}{l}\text { Middle-aged participants with a } \\
\text { good level of fitness }(n=132)\end{array}$ & $100 / 32$ & No sex differences & $\begin{array}{c}\text { Not validated among patients } \\
\text { with CVD }\end{array}$ \\
\hline \multicolumn{5}{|c|}{ Additional heart rate prediction equations for monitoring exercise intensity } \\
\hline Fox et al. ${ }^{95}(220-$ age $)$ & Men, age $<65$ years & Men only & Easy to use & $\begin{array}{c}\text { Overestimates heart rate peak } \\
\text { among older adults age } \pm 40 \\
\text { years } 96,97\end{array}$ \\
\hline Tanaka et al. ${ }^{96}(208-0.7 \times$ age $)$ & $\begin{array}{c}\text { Meta-analysis ( } \mathrm{n}=18,712 \\
\text { healthy adults) along with a } \\
\text { prospective study ( } 514 \text { healthy } \\
\text { adults) }\end{array}$ & Not reported & $\begin{array}{l}\text { Can predict heart rate peak } \\
\text { among older adults regardless of } \\
\operatorname{sex}_{96}\end{array}$ & $\begin{array}{c}\text { Not validated among patients } \\
\text { with CVD }\end{array}$ \\
\hline $\begin{array}{l}\text { Karvonen et al. }{ }^{98} \\
(220-\text { age }- \text { resting heart rate })\end{array}$ & Males, age 20 to 23 years $(n=6)$ & $6 / 0$ & $\begin{array}{c}\text { Helped establish exercise training } \\
\text { intensities: } \\
\text { Light }=30 \%-40 \% \mathrm{HRR} \\
\text { Moderate }=40 \%-60 \% \mathrm{HRR} \\
\text { Vigorous }=60 \%-90 \% \mathrm{HRR}\end{array}$ & $\begin{array}{l}\text { Can over- or underestimate } \\
\text { exercise intensity in certain } \\
\text { patients }\end{array}$ \\
\hline
\end{tabular}

CVD, cardiovascular disease; HRR, heart rate reserve.

CVD taking HR blunting medications (ie, beta-blockers), ${ }^{69}$ as they limit the ability to use other methods to monitor exercise intensity, such as HR equations.

Talk test. The talk test is an easy-to-use, inexpensive, and valid tool to monitor exercise intensity among patients with CVD. ${ }^{67,70-72}$ The talk test can be used when exercising at home with a partner, by self-determining whether comfortable speech is possible, difficult, or not possible, corresponding to light-, moderate-, and high intensity, respectively. During athome exercise without a partner, the talk test can be implemented by self-reflecting or actively determining whether comfortable speech is possible. When prescribing intensity using the talk test, those with CVD should be encouraged to exercise at a moderate intensity (ie, maintaining conversation is possible). The talk test has particular applicability during a pandemic. Advice regarding the use of this "instrument" can be provided simply; it requires little instruction and does not rely on calculations of HR or estimations of exertion (which can be perplexing and troublesome for many patients).

Heart rate equations. Exercise intensity is frequently prescribed and monitored using $\mathrm{HR}$ or oxygen uptake $\left(\mathrm{VO}_{2}\right)$ values. This measure is based on the observed direct and proportional increase in $\mathrm{HR}$ and $\mathrm{VO}_{2}$ during dynamic, aerobic exercise in women ${ }^{1}$ and men. ${ }^{2}$ This approach may lead to an under- or over-prescription of exercise intensity in patients taking medications (eg, $\beta$-blockers) that blunt HR responses, or when the exercise session leads to a disproportionate increase in HR (eg, aerobic dance exercise, high intensity exercise). ${ }^{3}$ Table 4 highlights our recommended HR equation for patients with CVD and provides additional equations that may be used to predict HR during exercise.

Wearable technologies. Wearables are available in a variety of modes (eg, smartwatches, smart patches, smart phones). These technologies provide an easy-to-use method of monitoring and receiving feedback on numerous physical activity parameters including $\mathrm{HR}$, heart rhythm, walking/running distance, walking/running speed, and steps taken. ${ }^{73,74}$ The reliability, validity, cost-effectiveness, and features of these technologies vary; thus, interpretation of the results produced by such devices, especially HR, should be performed cautiously. ${ }^{75,76}$ During a period when many challenges exist, not the least of which may be financial, the cost of such technologies may be a barrier to their use.

Time. Time refers to minutes spent engaging in exercise per session and/or throughout 1 week. Exercise guidelines recommend at least 150 minutes of MVPA per week, which aligns with 5,400-7,900 steps per day. ${ }^{7}$

Emerging evidence has demonstrated that any level of activity is superior to being sedentary, and that frequent, short-duration sessions of high intensity may effectively and efficiently enhance health. ${ }^{16,78,79}$ A higher total volume of MVPA is associated with many health benefits, including improvements in anxiety, depression, quality of life, cardiorespiratory fitness, blood pressure, and blood lipid levels. ${ }^{58}$ Shorter bouts of exercise (eg, $<10$ minutes) may initially be more feasible for those who are less fit, can elicit the aforementioned improvements in mental and physical health, and contribute to increasing the total volume of exercise. ${ }^{78}$ Short bouts of exercise throughout the day can also promote the interruption of prolonged sitting. Interval training is a time-efficient mode of structured exercise comprised of short bouts of increased-intensity activity followed by intermittent recovery periods. Intervals can vary in length (eg, 1 minute at an increased intensity, 2 minutes of active recovery; 1 minute at an increased intensity, 4 minutes of active recovery). Important to note is that exercise sessions of varying lengths (eg, long moderate-intensity continuous exercise, long/short high intensity interval training) have been shown to elicit similar physiological responses ${ }^{80}$; therefore, patient preferences merit careful consideration.

Type. Prescribing the type of exercise for those living with CVD should be, whenever possible, a collaborative process between the clinician and patient. Exercise enjoyment is a strong predictor of exercise participation, and greater exercise 
enjoyment is associated with more-frequent MVPA. "Fun" and "feasibility" are important determinants of sustained patterns of physical activity, so clinicians must be particularly aware of the dangers of "medicalizing" physical activity and provide physical activity guidance that is realistic, comprehensible, and in keeping with the circumstances and preferences of their patients. During the pandemic, creativity may be required to ensure appropriate and enjoyable physical activity (eg, virtual activity sessions with a friend, or timelimited challenges such as holding a wall-sit for the duration of 2 television commercials). Listening to music and watching television can be done during exercise at home and have been associated with superior mood and greater exercise enjoyment. ${ }^{82,83}$ During the COVID-19 pandemic, various exercise classes and cardiac rehabilitation programs have transitioned to online platforms. Virtual exercise classes (eg, those offered through cardiac rehabilitation programs, such as the University of Ottawa Heart Institute Heart Wise Exercise, ${ }^{84}$ community programs, or local fitness centres) may allow for those living with stable CVD to participate in structured programs with a trained instructor and permit social interaction (eg, viewing others on the screen, chatting after the class online). An example of an exercise prescription for patients with CVD is provided in Supplemental Material S3. Supplemental Tables S1 and S2 provide examples of exercise prescription for those with low and moderate levels of fitness and can be modified based on individual needs. Supplemental Table S3 provides an example of a physical activity log for tracking daily and weekly activity.

\section{Resistance, flexibility, and balance training}

Muscular strength and endurance, flexibility, and balance are integral elements for improving and maintaining functional fitness, reducing CVD risk factors, and managing chronic diseases. ${ }^{85}$ For many patients with CVD, an emphasis on "repetition" rather than "resistance" may be appropriate to ensure safety during muscular strength and endurance exercise. Patients with CVD should aim to complete 10-15 repetitions and 2-3 sets using a weight or resistance that can be comfortably repeated with proper form, with $\leq 90$-second rest intervals between sets, on 2 to 3 occasions per week. ${ }^{86}$ Body weight strength-training exercises can be modified to suit individuals of varying fitness levels (eg, wall push-ups, sitto-stand, or chair squats). Additional exercises, and flexibilityand balance-training activities and instructions, can be found for free via the Osteoporosis Canada website. ${ }^{87}$ The use of common household items, such as soup cans and water bottles, can be incorporated into strength-training exercises for added resistance (eg, bicep curls with soup cans). For patients with access to resistance bands or free-weights, strengthtraining exercises can be prescribed based on appropriate tension (resistance bands) and weight (free-weights) that allows for the completion of 10-15 repetitions and 2-3 sets of the exercise with proper technique (eg, appropriate range of motion, avoiding the Valsalver maneuver). For many who may be unfamiliar with the practice or precepts of resistance training, the provision of simple guidelines and examples regarding home-based activities may be a practical approach during a pandemic to ensuring that the benefits of such activities are more generally available.

\section{Sleep}

A regularly physically active lifestyle is key for sleep health. Recent systematic reviews and meta-analyses have shown that exercise improves many sleep outcomes. ${ }^{8,89}$ Physical activity interventions involving middle-aged and older adults showed strong positive effects on sleep efficiency and duration (regardless of the intensity and mode of activity) among those suffering from disease, such as CVD, and reporting unhealthy sleep. ${ }^{88}$

Practical recommendations or strategies to manage sleep disturbances during COVID-19 include the following: (i) prioritizing sleep and striving for 7-9 hours per night of sleep; (ii) maintaining a sleep routine, with consistent go-to-bed and wake-up times; (iii) ensuring as much daylight exposure as possible; (iv) avoiding use of digital devices (eg, a cellphone) in the bedroom or near bedtime; and, (v) exercising regularly. ${ }^{28}$ If some of these behavioural sleep recommendations are challenging during the COVID-19 pandemic, adaptations to fit the needs of different individuals have recently been published. $^{90}$

Sleep health can be monitored easily at home using simple tools such as sleep diaries (ie, paper or electronic notebooks for recording hours of sleep and time in bed per day; Supplemental Appendix S2) or wearable technology. Examples of simple and validated questions to assess sleep health have recently been published. ${ }^{91}$ These questions can be answered in less than 2 minutes and provide information on key sleep health characteristics, such as sleep duration, sleep quality, sleep timing, daytime alertness, and absence of a sleep disorder (with desired answers).

\section{Discussion}

This review highlights the impact the COVID-19 pandemic continues to have on 24-hour movement behaviours and exercise, discusses how these changes negatively impact those living with CVD, and provides practical recommendations that can be provided to patients during these unprecedented times. An understanding of the tools available to each patient (eg, access to technologies, diaries/logs) will aid in recommending and monitoring exercise, sedentary behaviour, and sleep. The Supplementary Material S3 provided in this article can be used to guide low- to moderate-intensity exercise prescription for those with CVD who should reduce sedentary time, aim to get 7-9 hours of sleep per night, and accumulate at least 150 minutes of MVPA per week. Of note, evidence is emerging regarding the long-term symptoms associated with a previous COVID-19 infection that could have a negative impact on achieving and maintaining healthy 24-hour movement behaviours (eg, fatigue, breathlessness,); ${ }^{92}$ greater efforts to individualize recommendations regarding sedentary behaviour, sleep, and physical activity may therefore be warranted. Sedentary behaviour has increased amid the pandemic ${ }^{14}$ and is recognized as an independent risk factor for several CVDs, CVD risk factors (eg, atrial fibrillation, hypertension, dyslipidemia), and premature mortality. 39,53 Healthcare professionals working with those living with CVD can recommend breaking up sedentary time with movement of any intensity, and specific recommendations on MVPA should be provided. Monitoring sedentary time using technologies or diaries/logs can also be encouraged and 
reviewed by the patient and healthcare provider to ensure healthy 24-hour movement and exercise profiles during the pandemic.

\section{Conclusion}

Lamentably, COVID-19 and many of its consequences are a part of the foreseeable future. Recommendations for 24hour movement behaviours and exercise need to take into consideration both the current health climate and the unique challenges faced within clinical settings and our communities (eg, time, space, and/or financial restraints). Clinicians should be aware that communication of the importance of physical activity and the provision of clear, comprehensible, and practical advice are fundamental to responding to the challenges posed by the pandemic for those living with CVD.

\section{Funding Sources}

The authors have no funding sources to declare.

\section{Disclosures}

The authors have no conflicts of interest to disclose. The content and views expressed in this article are those of the authors and do not necessarily reflect those of the Government of Canada.

\section{References}

1. COVID-19 Coronavirus Pandemic. 2020. Available at: https://www. worldometers.info/coronavirus/. Accessed November 16, 2021.

2. Wang L, He W, Yu X, et al. Coronavirus disease 2019 in elderly patients: characteristics and prognostic factors based on 4-week follow-up. J Infect 2020;80:639-45.

3. Liu H, Gai S, Wang X, et al. Single-cell analysis of SARS-CoV-2 receptor ACE2 and spike protein priming expression of proteases in the human heart. Cardiovasc Res 2020;116:1733-41.

4. Moulson N, Bewick D, Selway T, et al. Cardiac rehabilitation during the COVID-19 era: guidance on implementing virtual care. Can J Cardiol 2020;36:1317-21.

5. Hall G, Laddu DR, Phillips SA, Lavie CJ, Arena R. A tale of two pandemics: How will COVID-19 and global trends in physical inactivity and sedentary behavior affect one another? Progr Cardiovasc Dis 2021;64: 108-10.

6. Lippi G, Henry BM, Sanchis-Gomar F. Physical inactivity and cardiovascular disease at the time of coronavirus disease 2019 (COVID-19). Eur J Prevent Cardiol 2020;27:906-8.

7. Cellini N, Canale N, Mioni G, et al. Changes in sleep pattern, sense of time and digital media use during COVID-19 lockdown in Italy. J Sleep Res 2020;29:e13074.

8. Meyer J, McDowell C, Lansing J, et al. Changes in physical activity and sedentary behaviour due to the COVID-19 outbreak and associations with mental health in 3052 US adults. Int J Environ Res Public Health 2020;17:6469.

9. Colley RC, Bushnik T, Langlois K. Exercise and screen time during the COVID-19 pandemic. Health Rep 2020;31:3-11.

10. Edwardson CL, Gorely T, Davies MJ, et al. Association of sedentary behaviour with metabolic syndrome: a meta-analysis. PloS One 2012;7: e34916.
11. Teychenne M, Costigan SA, Parker K. The association between sedentary behaviour and risk of anxiety: a systematic review. BMC Public Health 2015;15:513.

12. Teychenne M, Ball K, Salmon J. Sedentary behavior and depression among adults: a review. Int J Behav Med 2010;17:246-54.

13. Patterson R, McNamara E, Tainio M, et al. Sedentary behaviour and risk of all-cause, cardiovascular and cancer mortality, and incident type 2 diabetes: a systematic review and dose response meta-analysis. Eur J Epidemiol 2018;33:811-29.

14. Faulkner G, Rhodes RE, Vanderloo LM, et al. Physical activity as a coping strategy for mental health due to the COVID-19 virus: a potential disconnect among Canadian adults? Front Commun 2020:5:571833.

15. Evenson KR, Butler EN, Rosamond WD. Prevalence of physical activity and sedentary behavior among adults with cardiovascular disease in the United States. J CardiopulmRehabil Prevent 2014;34:406-19.

16. Ekelund U, Tarp J, Steene-Johannessen J, et al. Dose-response associations between accelerometry measured physical activity and sedentary time and all cause mortality: systematic review and harmonised metaanalysis. BMJ 2019;366:14570.

17. Warburton DER, Bredin SSD. Health benefits of physical activity: a systematic review of current systematic reviews. Curr Opin Cardiol 2017;32:541-56.

18. Dibben GO, Dalal HM, Taylor RS, et al. Cardiac rehabilitation and physical activity: systematic review and meta-analysis. Heart 2018;104: $1394-402$.

19. Lee HK, Hwang IH, Kim SY, et al. The effect of exercise on prevention of the common cold: a meta-analysis of randomized controlled trial studies. Korean J Fam Med 2014;35:119-26.

20. Nieman DC, Henson DA, Austin MD, et al. Upper respiratory tract infection is reduced in physically fit and active adults. Bri J Sports Med 2011;45:987-92.

21. Brawner CA, Ehrman JK, Bole S, et al. Maximal exercise capacity is inversely related to hospitalization secondary to coronavirus disease 2019 . Mayo Clin Proc 2021;96:32-9.

22. Sallis R, Young DR, Tartof SY, et al. Physical inactivity is associated with a higher risk for severe COVID-19 outcomes: a study in 48440 adult patients. Br J Sports Med 2021;55:1099-105.

23. Anderson L, Taylor RS. Cardiac rehabilitation for people with heart disease: an overview of Cochrane systematic reviews. Cochrane Database Syst Rev, 2014Cd011273.

24. Yohannes AM, Doherty P, Bundy C, et al. The long-term benefits of cardiac rehabilitation on depression, anxiety, physical activity and quality of life. J Clin Nurs 2010;19:2806-13.

25. Ding D, del Pozo Cruz B, Green MA, Bauman AE. Is the COVID-19 lockdown nudging people to be more active: a big data analysis. $\mathrm{Br} \mathrm{J}$ Sports Med 2020;54:1183-4.

26. King AJ, Burke LM, Halson SL, et al. The challenge of maintaining metabolic health during a global pandemic. Sports Med 2020;50: 1233-41.

27. Krittanawong C, Virk HUH, Narasimhan B, et al. Coronavirus disease 2019 (COVID-19) and cardiovascular risk: a meta-analysis. Progr Cardiovasc Dis 2020;63:527-8.

28. Morin CM, Carrier J, Bastien C, et al. Sleep and circadian rhythm in response to the COVID-19 pandemic. Can J Public Health 2020;111: $654-7$. 
29. Chaput J-P, Dutil C, Featherstone R, et al. Sleep duration and health in adults: an overview of systematic reviews. Appl Physiol Nutr Metab 2020;45(Suppl 2):S218-31.

30. St-Onge M-P, Grandner MA, Brown D, et al. Sleep duration and quality: impact on lifestyle behaviors and cardiometabolic health: a scientific statement from the American Heart Association. Circulation 2016;134:e367-86.

31. Kuehn BM. Sleep duration linked to cardiovascular disease. Circulation 2019;139:2483-4.

32. Advani I, Gunge D, Banks S, et al. Is increased sleep responsible for reductions in myocardial infarction during the COVID-19 pandemic? Am J Cardiol 2020;131:128-30.

33. Grøntved A, Hu FB. Television viewing and risk of type 2 diabetes, cardiovascular disease, and all-cause mortality: a meta-analysis. JAMA 2011;305:2448-55.

34. Koster A, Caserotti P, Patel KV, et al. Association of sedentary time with mortality independent of moderate to vigorous physical activity. PloS One 2012;7:e37696.

35. Bakker EA, van Bakel BMA, Aengevaeren WRM, et al. Sedentary behaviour in cardiovascular disease patients: risk group identification and the impact of cardiac rehabilitation. Int J Cardiol 2021;326:194-201.

36. Ekelund U, Tarp J, Fagerland MW, et al. Joint associations of accelerometer-measured physical activity and sedentary time with allcause mortality: a harmonised meta-analysis in more than 44,000 middle-aged and older individuals. Br J Sports Med 2020;54:1499-506.

37. Guthold R, Stevens GA, Riley LM, et al. Worldwide trends in insufficient physical activity from 2001 to 2016: a pooled analysis of 358 population-based surveys with 1.9 million participants. Lancet Glob Health 2018;6:e1077-86.

38. Owen N, Healy GN, Matthews CE, et al. Too much sitting: the population health science of sedentary behavior. Exerc Sport Sci Rev 2010;38:105-13.

39. Patterns of sedentary behavior and mortality in U.S. middle-aged and older adults. Ann Intern Med 2017;167:465-75.

40. Kallings LV, Sierra Johnson J, Fisher RM, et al. Beneficial effects of individualized physical activity on prescription on body composition and cardiometabolic risk factors: results from a randomized controlled trial. Eur J Cardiovasc Prevent Rehabil 2009;16:80-4.

41. Dunstan DW, Thorp AA, Healy GN. Prolonged sitting: Is it a distinct coronary heart disease risk factor? Curr Opin Cardiol 2011;26:412-9.

42. Tison GH, Avram R, Kuhar P, et al. Worldwide effect of COVID-19 on physical activity: a descriptive study. Ann Intern Med 2020;173:767-70.

43. Tudor-Locke C, Craig CL, Thyfault JP, Spence JC. A step-defined sedentary lifestyle index: < 5000 steps/day. Appl Physiol Nutr Metab 2013;38:100-14.

44. World Health Organization. WHO Guidelines on Physical Activity and Sedentary Behaviour. 2020. Available at: https:/www.who.int/ publications/i/item/9789240015128. Accessed August 10, 2021.

45. Canadian Society for Exercise Physiology. 24-hour movement guideline for adults (18-64 years and 65+ years). Available at: https:// csepguidelines.ca/guidelines/adults-18-64/. Accessed August 10, 2021.

46. Gardner B, Smith L, Lorencatto F, et al. How to reduce sitting time? A review of behaviour change strategies used in sedentary behaviour reduction interventions among adults. Health Psychol Rev 2016;10: 89-112.

47. Prince SA, Reed JL, Cotie LM, et al. Results of the sedentary intervention trial in cardiac rehabilitation (SIT-CR Study): a pilot randomized controlled trial. Int J Cardiol 2018;269:317-24.

48. Rosenberg DE, Lee AK, Anderson M, et al. Reducing sedentary time for obese older adults: protocol for a randomized controlled trial. JMIR Res Protoc 2018;7:e23.

49. Dunstan DW, Kingwell BA, Larsen R, et al. Breaking up prolonged sitting reduces postprandial glucose and insulin responses. Diabetes Care 2012;35:976-83.

50. Canadian Society for Exercise Physiology, Get Active Questionnaire. Available at: https://csep.ca/wp-content/uploads/2021/05/ GETACTIVEQUESTIONNAIRE_ENG.pdf. Accessed August 10, 2021.

51. American College of Sports Medicine, Exercise Preparticipation Health Screening. Available at: https://www.acsm.org/blog-detail/acsm-certifiedblog/2018/02/01/exercise-preparticipation-screening-removing-barriersinitiating-exercise. Accessed August 10, 2021.

52. Riebe D, Franklin BA, Thompson PD, et al. Updating ACSM's Recommendations for Exercise Preparticipation Health Screening. Med Sci Sports Exerc 2015;47:2473-9.

53. Stone JA. Canadian guidelines for cardiac rehabilitation and cardiovascular disease prevention are available. J Cardiopulm Rehabil 2001;21: $344-5$.

54. Ismail H, McFarlane JR, Dieberg G, et al. Exercise training program characteristics and magnitude of change in functional capacity of heart failure patients. Int J Cardiol 2014;171:62-5.

55. Nieuwland W, Berkhuysen MA, van Veldhuisen DJ, et al. Differential effects of high-frequency versus low-frequency exercise training in rehabilitation of patients with coronary artery disease. J Am Coll Cardiol 2000;36:202-7.

56. Kim K, Choi S, Hwang SE, et al. Changes in exercise frequency and cardiovascular outcomes in older adults. Eur Heart J 2020;41:1490-9.

57. Carpio-Rivera E, Moncada-Jiménez J, Salazar-Rojas W, et al. Acute effects of exercise on blood pressure: a meta-analytic investigation. Arq Bras Cardiol 2016;106:422-33.

58. Terada T, Friesen A, Chahal BS, et al. Exploring the variability in acute glycemic responses to exercise in type 2 diabetes. J Diabetes Res 2013;2013:591574.

59. Basso JC, Suzuki WA. The effects of acute exercise on mood, cognition, neurophysiology, and neurochemical pathways: a review. Brain Plast 2017;2:127-52.

60. Fagard RH. Exercise characteristics and the blood pressure response to dynamic physical training. Med Sci Sports Exerc 2001;33(6 Suppl): S484-92. discussion S93-S94.

61. Mann S, Beedie C, Jimenez A. Differential effects of aerobic exercise, resistance training and combined exercise modalities on cholesterol and the lipid profile: review, synthesis and recommendations. Sports Med 2014; 44:211-21.

62. Umpierre D, Ribeiro PA, Schaan BD, et al. Volume of supervised exercise training impacts glycaemic control in patients with type 2 diabetes: a systematic review with meta-regression analysis. Diabetologia 2013;56: $242-51$. 
63. Berkhuysen MA, Nieuwland W, Buunk BP, et al. Effect of high-versus low-frequency exercise training in multidisciplinary cardiac rehabilitation on health-related quality of life. J Cardiopulm Rehabil 1999;19:22-8.

64. Broman-Fulks JJ, Abraham CM, Thomas K, et al. Anxiety sensitivity mediates the relationship between exercise frequency and anxiety and depression symptomology. Stress Health 2018;34:500-8.

65. Hansen D, Abreu A, Ambrosetti M, et al. Exercise intensity assessment and prescription in cardiovascular rehabilitation and beyond: why and how: a position statement from the Secondary Prevention and Rehabilitation Section of the European Association of Preventive Cardiology. Eur J Prev Cardiol 2021 Jun 2.

66. Stamford BA. Validity and reliability of subjective ratings of perceived exertion during work. Ergonomics 1976;19:53-60.

67. Reed JL, Pipe AL. The talk test: a useful tool for prescribing and monitoring exercise intensity. Curr Opin Cardiol 2014;29:475-80.

68. Borg GA. Psychophysical bases of perceived exertion. Med Sci Sports Exerc 1982;14:377-81.

69. Faulkner J, Eston R. Overall and peripheral ratings of perceived exertion during a graded exercise test to volitional exhaustion in individuals of high and low fitness. Eur J Appl Physiol 2007;101:613-20.

70. Petersen AK, Maribo T, Hjortdal VE, et al. Intertester reliability of the talk test in a cardiac rehabilitation population. J Cardiopulm Rehabil Prev 2014;34:49-53.

71. Zanettini R, Centeleghe P, Franzelli C, et al. Validity of the talk test for exercise prescription after myocardial revascularization. Eur J Prev Cardiol 2013;20:376-82.

72. Voelker S, Foster C, Porcari J, et al. Relationship between the talk test and ventilatory threshold in cardiac patients. Clin Exerc Physiol 2002;4:120-3.

73. Düking P, Holmberg HC, Sperlich B. Instant biofeedback provided by wearable sensor technology can help to optimize exercise and prevent injury and overuse. Front Physiol 2017;8:167.

74. Hosseinpour M, Terlutter R. Your personal motivator is with you: a systematic review of mobile phone applications aiming at increasing physical activity. Sports Med 2019;49:1425-47.

75. Duking P, Giessing L, Frenkel MO, et al. Wrist-worn wearables for monitoring heart rate and energy expenditure while sitting or performing light-to-vigorous physical activity: validation study. JMIR Mhealth and Uhealth 2020;8:e16716.

76. Düking P, Hotho A, Holmberg HC, et al. Comparison of non-invasive individual monitoring of the training and health of athletes with commercially available wearable technologies. Front Physiol 2016;7:71.

77. American College of Sports Medicine. ACSM's Guidelines for Exercise Testing and Prescription. Philadelphia, PA: Wolters Kluwer, 2018:160.

78. Piercy KL, Troiano RP, Ballard RM, et al. The physical activity guidelines for Americans. JAMA 2018;320:2020-8.

79. Dempsey PC, Strain T, Khaw K-T, et al. Prospective associations of accelerometer-measured physical activity and sedentary time with incident cardiovascular disease, cancer, and all-cause mortality. Circulation 2020;141:1113-5.

80. von Korn P, Keating S, Mueller S, et al. The effect of exercise intensity and volume on metabolic phenotype in patients with metabolic syndrome: a randomized controlled trial. MetabSyndr Relat Disord 2021;19:107-14.
81. Lewis BA, Williams DM, Frayeh A, et al. Self-efficacy versus perceived enjoyment as predictors of physical activity behaviour. Psychol Health 2016;31:456-69.

82. Murrock CJ. The effects of music on the rate of perceived exertion and general mood among coronary artery bypass graft patients enrolled in cardiac rehabilitation phase II. Rehabil Nurs 2002;27:227-31.

83. Rider BC, Bassett DR, Strohacker K, et al. Psycho-physiological effects of television viewing during exercise. J Sports Sci Med 2016;15:524-31.

84. Reed JL, Harris JM, Midence L, et al. Evaluating the Heart Wise Exercise program: a model for safe community exercise programming. BMC Public Health 2016;16:190.

85. Pollock ML, Evans WJ. Resistance training for health and disease: introduction. Med Sci Sports Exerc 1999;31:10-1.

86. Fleck SJ. Designing Resistance Training Programs. 2nd ed. Champaign, IL: Human Kinetics, 1997.

87. Osteoporosis Canada website. Available at: https://osteoporosis.ca/ exercise-recommendations/. Accessed August 10, 2021.

88. Dolezal BA, Neufeld EV, Boland DM, et al. Interrelationship between sleep and exercise: a systematic review. Adv Prev Med 2017;2017: 1364387.

89. Vanderlinden J, Boen F, van Uffelen JGZ. Effects of physical activity programs on sleep outcomes in older adults: a systematic review. Int J Behav Nutr Phys Activ 2020;17:11.

90. Altena E, Baglioni C, Espie CA, et al. Dealing with sleep problems during home confinement due to the COVID-19 outbreak: practical recommendations from a task force of the European CBT-I Academy. J Sleep Res 2020;29:e13052.

91. Chaput J-P, Shiau J. Routinely assessing patients' sleep health is time well spent. Prev Med Rep 2019;14:100851.

92. Aucott JN, Rebman AW. Long-haul COVID: Heed the lessons from other infection-triggered illnesses. Lancet 2021;397:967-8.

93. Pandey A, Salahuddin U, Garg S, et al. Continuous dose-response association between sedentary time and risk for cardiovascular disease: a meta-analysis. JAMA Cardiol 2016;1:575-83.

94. Gellish RL, Goslin BR, Olson RE, et al. Longitudinal modeling of the relationship between age and maximal heart rate. Med Sci Sports Exerc 2007;39:822-9.

95. Fox SM 3rd, Haskell WL. Physical activity and the prevention of coronary heart disease. Bull N Y Acad Med 1968;44:950-67.

96. Tanaka H, Monahan KD, Seals DR. Age-predicted maximal heart rate revisited. J Am Coll Cardiol 2001;37:153-6.

97. Gulati M, Shaw LJ, Thisted RA, et al. Heart rate response to exercise stress testing in asymptomatic women: the st. James women take heart project. Circulation 2010;122:130-7.

98. Karvonen J, Vuorimaa T. Heart rate and exercise intensity during sports activities. Practical application. Sports Med 1988;5:303-11.

\section{Supplementary Material}

To access the supplementary material accompanying this article, visit CJC Open at https://www.cjcopen.ca/ and at https://doi.org/10.1016/j.cjco.2021.08.010. 